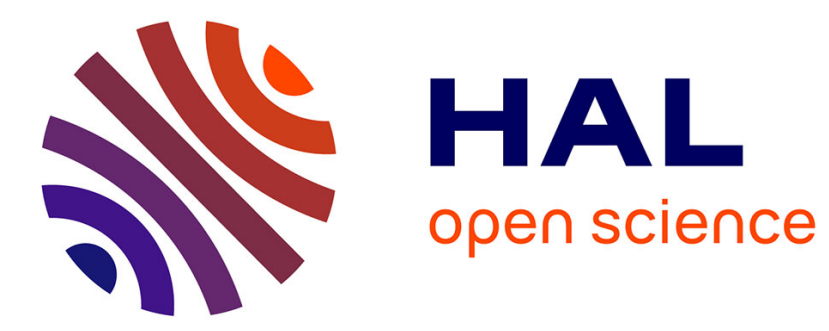

\title{
Aminoglycosides in Critically Ill Septic Patients With Acute Kidney Injury Receiving Intermittent Hemodialysis: A Multicenter, Observational Study
}

Alexandre Boyer, Jean-François Timsit, Kada Klouche, Emmanuel Canet, Thuy-Nga Phan, Julien Bohé, Sebastien Rubin, Arthur Orieux, Alexandre Lautrette, Didier Gruson, et al.

\section{To cite this version:}

Alexandre Boyer, Jean-François Timsit, Kada Klouche, Emmanuel Canet, Thuy-Nga Phan, et al.. Aminoglycosides in Critically Ill Septic Patients With Acute Kidney Injury Receiving Intermittent Hemodialysis: A Multicenter, Observational Study. Clinical Therapeutics, 2021, 10.1016/j.clinthera.2021.04.015 . hal-03258710

\author{
HAL Id: hal-03258710 \\ https://hal.science/hal-03258710
}

Submitted on 13 Jun 2021

HAL is a multi-disciplinary open access archive for the deposit and dissemination of scientific research documents, whether they are published or not. The documents may come from teaching and research institutions in France or abroad, or from public or private research centers.
L'archive ouverte pluridisciplinaire HAL, est destinée au dépôt et à la diffusion de documents scientifiques de niveau recherche, publiés ou non, émanant des établissements d'enseignement et de recherche français ou étrangers, des laboratoires publics ou privés. 


\title{
Aminoglycosides in Critically Ill Septic Patients With Acute Kidney Injury Receiving Intermittent Hemodialysis: A Multicenter, Observational Study
}

\author{
Alexandre Boyer, M.D, Ph.D ${ }^{1}$; Jean-François Timsit, M.D, Ph.D²; Kada Klouche, M.D, \\ Ph.D ${ }^{3}$; Emmanuel Canet, M.D, Ph.D ${ }^{4}$; Thuy-nga Phan, M.D ${ }^{5}$; Julien Bohé, M.D, Ph.D ${ }^{5}$; \\ Sebastien Rubin, M.D ${ }^{6}$; Arthur Orieux, M.D ${ }^{6}$; Alexandre Lautrette, M.D, Ph.D ${ }^{7}$; \\ Didier Gruson, M.D, Ph.D ${ }^{1}$; and Bertrand Souweine, M.D, Ph.D ${ }^{7}$ \\ ${ }^{1}$ Service de Médecine Intensive Réanimation, CHU Bordeaux, Bordeaux, France; ${ }^{2}$ Service de \\ Réanimation Médicale, CHU Grenoble Alpes, La Tronche, France; ${ }^{3}$ Service Médecine \\ Intensive Réanimation, CHU Montpellier, Montpellier, France; ${ }^{4}$ Service Médecine Intensive \\ Réanimation, Hôpital Saint-Louis (APHP), Paris, France; ${ }^{5}$ Service d'Anesthésie et \\ Réanimation Médicale et Chirurgicale, Centre Hospitalier Lyon Sud, Lyon, France; ${ }^{6}$ Service \\ de Néphrologie, CHU Bordeaux, Bordeaux, France; and ${ }^{7}$ Service de Médecine Intensive \\ Réanimation, CHU Gabriel-Montpied, Clermont-Ferrand, France
}

\section{ABSTRACT}

Purpose: Data on aminoglycoside stewardship in critically ill septic patients with acute kidney injury (AKI) needing intermittent hemodialysis (IH) are scarce. The first objective of the study was to evaluate whether aminoglycoside administration occurs before vs after $\mathrm{IH}$ in the real-life management of critically ill septic patients with AKI needing IH. The second objective was to assess the delay in achieving a potential reinjection window for a second dose of aminoglycoside, which should be obtained with a postdialysis vs predialysis regimen.

Methods: A post hoc observational analysis of a multicenter randomized trial of critically ill patients with AKI needing renal replacement therapy was conducted. Inclusion criteria consisted of any patients receiving $\mathrm{IH}$ for AKI during an antimicrobial therapy for a septic episode.

Findings: Among 206 of 341 septic patients (60\%) receiving aminoglycosides, 90 underwent $\mathrm{IH}$ (46 with previous continuous renal replacement therapy and 44 without). Amikacin and gentamicin were administered for a mean (SD) of 2.2 (1.5) and 2.5 (2.1) days with mean (SD) doses of 20.6 (6.6) and 5.4 (2.5) $\mathrm{mg} / \mathrm{kg}$, respectively. In the 44 patients undergoing exclusive $\mathrm{IH}$, aminoglycosides were administered in a predialysis in $53 \%$ of episodes versus $35 \%$ in a postdialysis schedule. The first $\mathrm{C}_{\min }$ target was obtained earlier with a predialysis vs postdialysis schedule (33.9 [14.2] hours vs 50.9 [12.2] hours, $P=0.009$ ).

Implications: Despite being less frequently used than a predialysis schedule, the postdialysis administration of aminoglycosides remains a regular practice in the intensive care unit. A predialysis schedule of administration in $\mathrm{IH}$ reduces the interval time to tolerable aminoglycoside redosing. (Clin Ther. 2021;000:1-7.) (C) 2021 Elsevier Inc.

Keywords: acute kidney injury, aminoglycosides, critical care, intermittent haemodialysis, renal replacement therapy, sepsis.

\section{INTRODUCTION}

Acute kidney injury (AKI) occurs in $35 \%$ to $50 \%$ of patients in the 48 hours of intensive care unit (ICU) admission, with $10 \%$ of these patients requiring renal replacement therapy (RRT). ${ }^{1}$ Intermittent hemodialysis (IH) represents one-quarter of the chosen RRT modality. ${ }^{2}$

A decade ago, the treatment of sepsis with aminoglycosides entered the high-dose once-daily 
(HDOD) era $^{3}$ (ie, $20-25 \mathrm{mg} / \mathrm{kg}$ of amikacin and $7 \mathrm{mg} / \mathrm{kg}$ of gentamicin). Despite aminoglycosidesassociated nephrotoxicity, the role of aminoglycosides in the occurrence of AKI in ICU patients with shock has been controversial. ${ }^{4}$ ICU physicians are thus not discouraged to use them in this context. ${ }^{3}$

Historically, when lower doses were recommended, aminoglycosides were administered just at the end of the IH session ${ }^{5-7}$ as recommended by the manufacturer. ${ }^{8}$ However, peak concentrations achieved by low doses did not achieve the desired $\mathrm{C}_{\max }$ :MIC ratios of 10:1 in most patients, especially in case of increased $V_{d}$ from fluid overload or sepsis ${ }^{9}$ On the basis of the assumption that both ototoxic and nephrotoxic risks depend on the $\mathrm{AUC}^{10,11}$ and that aminoglycoside efficacy depends on $\mathrm{C}_{\mathrm{msx}}$ /MIC, Matsuo et $\mathrm{al}^{12}$ were the first to propose a predialysis and increased dose of aminoglycosides, ${ }^{12}$ followed by other investigators. ${ }^{9}, 13-15$ This way intermittent dialysis could remove enough of aminoglycosides so that the total drug exposure of a higher dose remained similar to that achieved by a lower dose administered after a postdialysis regimen. For example, a $6-\mathrm{mg} / \mathrm{kg}$ predialysis dose achieved higher mean (SD) peaks than a $1.7-\mathrm{mg} / \mathrm{kg}$ postdialysis dose (31.0 [10.9] vs 8.8 [3.1] $\mathrm{kg} / \mathrm{L}$ ), with only a moderately increased mean (SD) AUC (190.8 [65] vs 135.0 [42.2] mg/h/L). ${ }^{15}$

Other authors question the benefit-risk balance of this new regimen; they suggest, based on animal models, that time above the MIC, which may be higher with the postdialysis regimen than with the predialysis one, remains the most reliable pharmacodynamic parameter of clinical efficacy. ${ }^{16}$ In an in vitro model of OXA-48-producing Klebsiella pneumoniae, the postdialysis regimen of amikacin was associated with the lowest enrichment of resistant subpopulations. ${ }^{17}$

Facing these conflicting views, to what extent the predialysis versus postdialysis schedules are now implemented in ICUs remains unknown. Moreover, how far a predialysis regimen, in removing enough of aminoglycosides, may allow an earlier aminoglycoside reinjection has not been described. The first objective of the study was to evaluate whether aminoglycoside administration occurs before versus after $\mathrm{IH}$ in the reallife management of critically ill septic patients with AKI needing IH. The second objective was to assess the delay in achieving a potential reinjection window for a second dose of aminoglycosides, which should be obtained with a postdialysis vs predialysis regimen.

\section{MATERIAL AND METHODS Study Design and Patients}

This study is a post hoc analysis of a multicenter ( $\mathrm{n}=16$ centers), randomized, controlled study ${ }^{18}$ of adults requiring RRT for AKI (Kidney Disease Improving Global Outcomes 3). In the present study, only 6 of the 16 centers accepted to participate. Only patients who presented with septic episodes needing antibiotics were eligible. To specifically meet the inclusion criteria, the time window of antibiotic exposure was $\leq 24$ hours before first RRT session (some antibiotic therapy could be initiated just before ICU admission) or after the first RRT session during their ICU stay. All episodes of antibiotic treatment stopped at the ICU admission were excluded as were patients with antibiotic treatment initiated more than 72 hours before the first RRT session. The study protocol was approved by the Sud-Est 1 Ethics Committee of France. Written informed consent was obtained from the patients or next of kin before inclusion.

\section{Interventions}

In the initial study, no other intervention than dialysis catheter lock was controlled. ${ }^{18}$ The modality (continuous RRT [CRRT] or IH) and timing of $\mathrm{IH}$ were left to the physicians' discretion as were antibiotic orders. Each episode of antibiotic treatment was screened, and factors associated with the decision of adding aminoglycosides or not to the empirical antimicrobial therapy were assessed via a closed questionnaire by physicians managing the patient. The HDOD regimen was used.

Monitoring of plasma aminoglycoside concentrations was left to the physician's discretion. All serum aminoglycoside concentrations were returned to the physician in a range of 1 to 6 hours according to the different centers. The different centers reported the same $C_{\max }(20-40 \mathrm{mg} / \mathrm{L}$ for gentamicin and $40-$ $80 \mathrm{mg} / \mathrm{L}$ for amikacin) and $\mathrm{C}_{\min }$ objectives $(0.5-2$ $\mathrm{mg} / \mathrm{L}$ for gentamicin and $2.5-5 \mathrm{mg} / \mathrm{L}$ for amikacin). The pharmacokinetic samples were determined at the pharmacology departments of each hospital by using a validated immunoassay method (QMS Amikacin Assay [Thermo Fisher Scientific, Waltham, Massachusetts] on an Olympus AU5400 [Beckman Coulter, Brea, California]).

\section{Definitions}

Sepsis was defined by a systemic inflammatory response syndrome and a suspected source of infection 


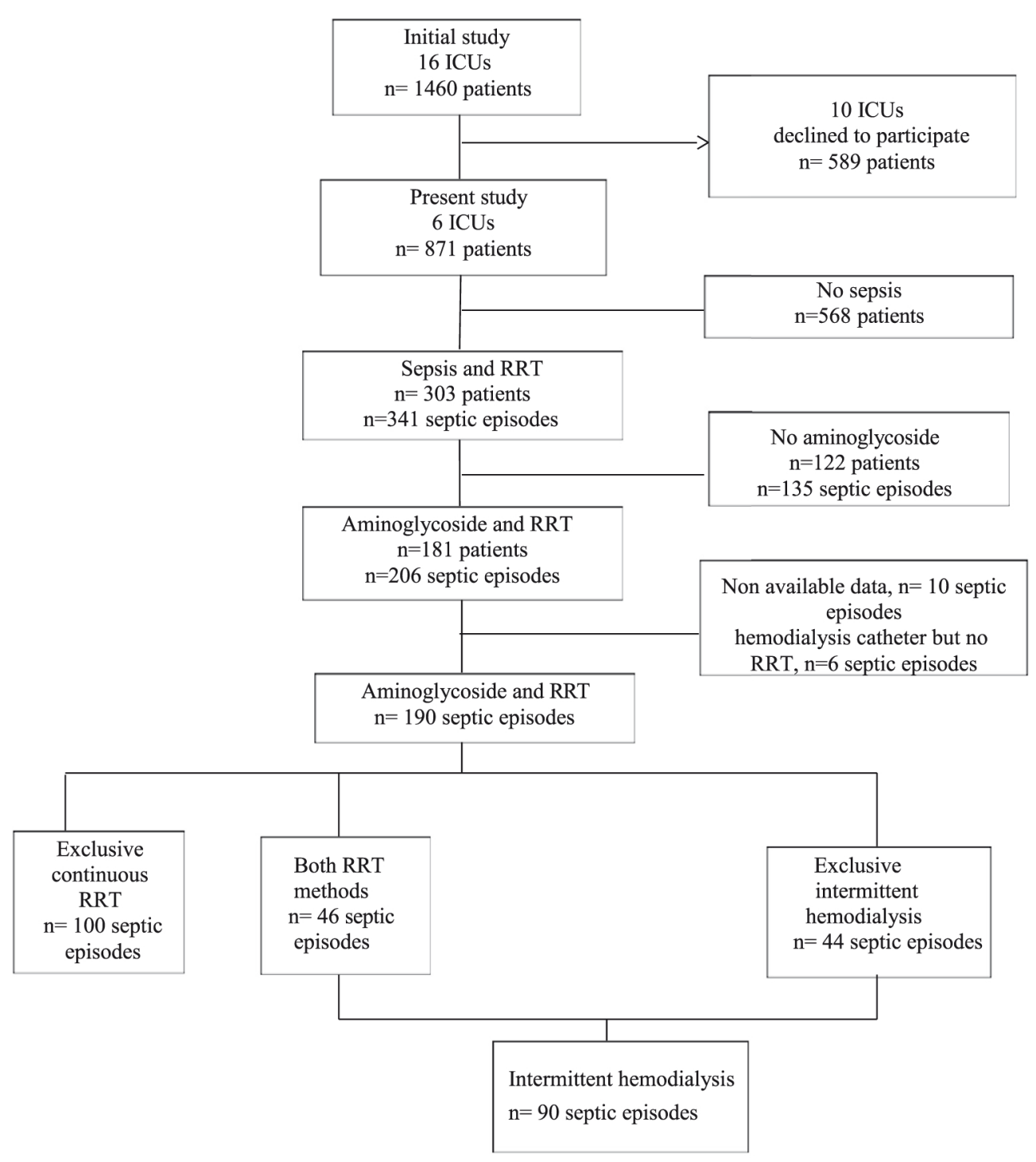

Figure. Study flow chart. ICU = intensive care unit; RRT = renal replacement therapy.

requiring an antimicrobial therapy according to bedside physicians. ${ }^{19}$ When a patient developed several distinct sepsis episodes and provided a washout period (without antibiotic) occurred between them, this was considered several different septic episodes, each being the object of a new inclusion, because the analyzed event was an episode of antibiotic-treated sepsis.

Infection site according to aminoglycoside tissue penetration was defined as follows ${ }^{20}$ : poor (cerebrospinal fluid and joint), middle (alveolar fluid, skin, or soft tissue), or good (abdominal, urinary tract, or blood). Successful reinjection corresponded to a new subsequent injection (after the first injection) preceded by an aminoglycoside $\mathrm{C}_{\min }$ dosage under the recommended target. For predialysis vs postdialysis aminoglycoside administration, an arbitrary threshold of 8 hours was selected to differentiate predialysis (hour 8 to dialysis) from postdialysis (dialysis to $\geq 16$ hours) administration.

\section{Outcomes}

For each septic episode, the incidence of predialysis versus postdialysis aminoglycoside administration was assessed. Aminoglycoside dosing was homogeneous among the different centers. $\mathrm{C}_{\max }, \mathrm{C}_{\min }, \mathrm{C}_{\text {intermediate }}$ (defined by a dosage of aminoglycoside concentrations 
Table I. Aminoglycoside administration and pharmacokinetic parameters.

\begin{tabular}{|c|c|c|c|}
\hline Variable & Amikacin & Gentamicin & $P$ \\
\hline \multicolumn{4}{|l|}{ Administration* } \\
\hline No. of episodes & 57 & 33 & \\
\hline No. of doses, mean (SD) & $20.6(6.6)$ & $5.4(2.5)$ & NA \\
\hline Episodes with only 1 dose, \% & 37 & 43 & 0.29 \\
\hline No. of dosing days, mean (SD) & $2.5(1.6)$ & $2.7(2.1)$ & 0.61 \\
\hline Interval between 2 doses, mean (SD), $\mathrm{d}$ & $1.7(1.0)$ & $1.7(1.1)$ & 0.80 \\
\hline \multicolumn{4}{|l|}{ Pharmacokinetic parameters $^{\dagger}$} \\
\hline No. of episodes & 27 & 17 & \\
\hline \multicolumn{4}{|l|}{$C_{\max }, \operatorname{mean}(S D)^{\ddagger}$} \\
\hline Before dialysis & $\begin{array}{l}67.6(28.6) \\
(n=19)\end{array}$ & $21.6(3.5)(n=4)$ & NA \\
\hline After dialysis & $26.0(7.3)(n=6)$ & $19.1(9.7)(n=10)$ & \\
\hline $\mathrm{C}_{\min }$, mean $(\mathrm{SD})^{\ddagger}$ & $3.7(2.4)$ & $2.0(0.8)$ & NA \\
\hline \multicolumn{4}{|c|}{ 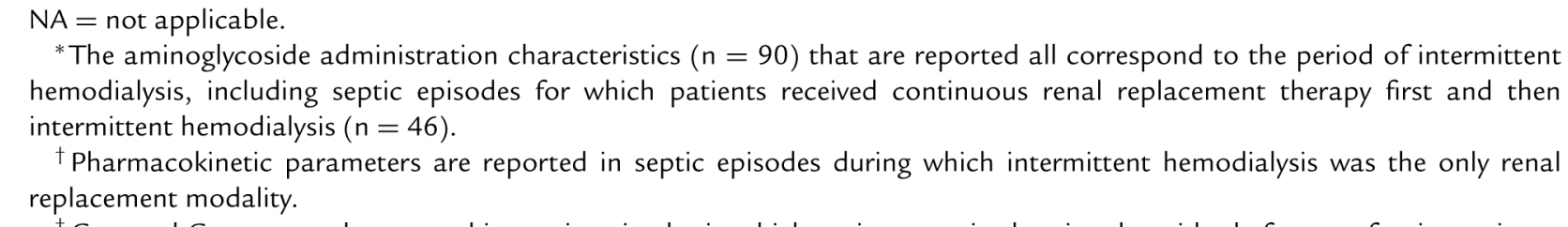 } \\
\hline
\end{tabular}

between $\mathrm{C}_{\max }$ and $\mathrm{C}_{\min }$ ) were assessed: amikacin or gentamicin levels were measured 1 hour $\left(\mathrm{C}_{\max }\right)$ after the onset of a 30-minute perfusion and within 2 hours before the next injection or at 24 hours in case of no reinjection $\left(\mathrm{C}_{\min }\right)$. The number of administrations, length of aminoglycoside treatment, and number of aminoglycoside injections (according to $\mathrm{C}_{\max }$ and $\mathrm{C}_{\min }$ ) matching with pharmacodynamic recommendations (amikacin: $\mathrm{C}_{\max }$ of $40-80 \mathrm{mg} / \mathrm{L}$ and $\mathrm{C}_{\min }<5 \mathrm{mg} / \mathrm{L}$; gentamicin: $C_{\max }$ of $20-30 \mathrm{mg} / \mathrm{L}$ and $C_{\min }<2 \mathrm{mg} / \mathrm{L}$ ) were assessed.

\section{Statistical Analysis}

Results are expressed as median (interquartile range). Continuous variables were compared using 2 tests: the Mann-Whitney-Wilcoxon test for independent variables and the Wilcoxon signed-rank test for the matched paired series. Categorical variables were compared using the Fisher exact test. All $P$ values and CIs were 2-tailed.

\section{RESULTS}

Eligible critically ill patients $(\mathrm{n}=303$ ) developed 341 septic episodes (Figure). Aminoglycosides, including gentamicin ( $\mathrm{n}=71)$, amikacin $(\mathrm{n}=145)$, or both $(\mathrm{n}=10)$, were administered in 206 septic episodes $(60 \%)$. Reasons for not adding aminoglycosides in the empirical antimicrobial therapy were no necessary combination (46\%), other nephrotoxic drugs (24\%), aminoglycoside nephrotoxicity $(21 \%)$, likely not susceptible species $(4 \%)$, decision of treatment withdrawal $(2 \%)$, poor penetration $(1 \%)$, and ototoxic risk $(1 \%)$.

Among 206 septic episodes, 90 corresponded to the inclusion criteria (half with exclusive IH and half with a combination of IH and CRRT) (Figure), with 16 of the 90 episodes occurring in the same patient with a mean (SD) interval of 16 (6) days (minimum of 8 days) between each. Mean (SD) blood flow was 246 (48) $\mathrm{mL} / \mathrm{min}$, mean (SD) dialysate flow was 582 (362) $\mathrm{mL} / \mathrm{min}$, mean (SD) fluid removal was 1400 (1300) $\mathrm{mL}$, and mean (SD) blood urea nitrogen was 20 (11) 


\begin{tabular}{|c|c|c|c|}
\hline Variable & $\begin{array}{l}\text { Predialysis regimen } \\
(n=23)\end{array}$ & $\begin{array}{l}\text { Postdialysis regimen } \\
(n=16)\end{array}$ & $P$ \\
\hline \multicolumn{4}{|l|}{ Patient-related factors } \\
\hline Male, \% & 74 & 67 & 0.98 \\
\hline SAPS II, mean (SD) & $77(18)$ & $73(13)$ & 0.52 \\
\hline SOFA score, mean $(\mathrm{SD})^{*}$ & $14.6(4.5)$ & $13.3(3.1)$ & 0.37 \\
\hline Weight, mean (SD), kg & $91(24)$ & $95(31)$ & 0.74 \\
\hline \multicolumn{4}{|l|}{ Factors related to septic episode } \\
\hline \multicolumn{4}{|l|}{ Infection site (according to AG tissue penetration), \% } \\
\hline Good (abdominal, urinary tract, or blood) & 58 & 42 & 0.82 \\
\hline Middle (alveolar fluid, skin, or soft tissue) & 26 & 33 & \\
\hline Poor (cerebrospinal fluid or joint) or no identified site & 16 & 24 & \\
\hline \multicolumn{4}{|l|}{ Final documentation, $\%$} \\
\hline Gram negative & 55 & 25 & 0.25 \\
\hline Gram positive & 25 & 42 & \\
\hline Other (fungi or virus) or no documentation & 20 & 33 & \\
\hline \multicolumn{4}{|l|}{ Concomitant nephrotoxic drug ( $\geq 1$ nephrotoxic drug), \% } \\
\hline Diuretics & 21 & 31 & 0.76 \\
\hline lode & 17 & 15 & \\
\hline Vancomycin & 28 & 23 & \\
\hline Amphotericin B & 3 & 0 & \\
\hline Angiotensin receptor blocker & 7 & 0 & \\
\hline No & 24 & 31 & \\
\hline
\end{tabular}

mmol/L before the session and $12(7) \mathrm{mmol} / \mathrm{L}$ after the session.

The mean (SD) amikacin and gentamicin doses were $20.6(6.6) \mathrm{mg} / \mathrm{kg}$ and $5.4(2.5) \mathrm{mg} / \mathrm{kg}$, respectively ( $\mathrm{n}=90$ septic episodes) (Table I), without difference in doses used in septic episodes of patients needing CRRT ( $\mathrm{n}=145$ (Figure) $(20.2$ [6.6] mg/kg and 6 [1.95] $\mathrm{mg} / \mathrm{kg}$, respectively). No significant difference in the mean (SD) number of aminoglycoside administration for 1 septic episode was observed (2.5 [1.6] for amikacin and $2.7[2.1]$ for gentamicin; $P=0.61$ ). Mean (SD) amikacin and gentamicin $\mathrm{C}_{\max }$ in patients receiving $\mathrm{IH}$ were of $55.6(20.8) \mathrm{mg} / \mathrm{L}$ and $20.2(7.8)$ $\mathrm{mg} / \mathrm{L}$, respectively, without significant difference with those of patients receiving CRRT. No difference was observed for the interval between 2 consecutive doses of amikacin versus gentamicin (Table II) or between patients receiving IH versus CRRT.

Data including the timing between aminoglycoside administrations and $\mathrm{IH}$ sessions could not be analyzed in 46 septic patients in whom aminoglycosides had been administered during CRRT and in whom aminoglycoside administration at the time of IH. In the 44 remaining episodes, $\mathrm{C}_{\max }$ and $\mathrm{C}_{\min }$ are reported in Table I. The perfusion was initiated before $\mathrm{IH}$ in 23 $(53 \%)$, with a mean (SD) interval time of $6.4(5.2)$ hours, during $\mathrm{IH}$ in $5(12 \%)$, and after $\mathrm{IH}$ in $16(36 \%)$, with a mean (SD) delay of 3.4 (4) hours. Table II lists the clinical characteristics of sepsis according to predialysis vs postdialysis administration. The mean (SD) time to the first $\mathrm{C}_{\min }$ target attainment was 33.9 (14.2) hours in the predialysis period versus 50.9 (12.2) 
hours in the postdialysis period of administration $(P=0.009)$.

\section{DISCUSSION}

To our knowledge, the present study is the first to report a multicenter, descriptive observation of aminoglycoside administration during $\mathrm{IH}$ in critically ill septic patients. Most previous studies have been conducted in quasi-experimental conditions. ${ }^{12,13,15,21}$ It is important to provide data exemplifying the real-life management of aminoglycosides. In patients receiving $\mathrm{IH}$, traditional practice included the administration of a postdialysis aminoglycoside corresponding to half the usual dose. ${ }^{22}$ More recently, a predialysis aminoglycoside administration schedule produced a $40 \%$ decrease of aminoglycoside AUC compared with postdialysis administration. ${ }^{12}$ However, the predialysis schedule is still controversial. ${ }^{16,17}$ In our study, not all physicians use it. In this study, we quantified its effect as a predialysis schedule translated to a better pharmacokinetic target attainment (mean [SD] time to the first $\mathrm{C}_{\min }$ target of 33.9 [14.2] hour in the predialysis period vs 50.9 [12.2] hours in the postdialysis period). This finding could encourage use of the predialysis administration schedule by physicians who intend to administer at least 2 aminoglycoside doses in patients with septic shock because physicians will rarely reinject aminoglycosides at 50 hours in critically ill patients (because their patient is now stable), whereas they may after 30 hours.

Our study has limitations. The pharmacokinetic properties of aminoglycosides can be modified by patient-related factors (eg, body mass index and chronic kidney disease), disease-related factors (eg, severity of sepsis, volume of fluid expansion, and acute kidney injury), and pathogen-related factors (MIC). Despite presentation by aminoglycoside type before vs after the IH regimen (Table II), no model accounting for individual patient or pathogen factors (no reported $\mathrm{C}_{\max } / \mathrm{MIC}$ ) was provided. Moreover, age of patients was not collected, although age can play a role in pharmacokinetic properties. The absence of systematic and individual pharmacokinetic assessment of aminoglycoside concentrations for each patient provides data of weaker evidence. This study is not a standardized, prospective study, and we cannot discard a selection bias in favor of the patients receiving the best care. The use of different dialyzers among the various participating centers could add potential confounding on the study findings. ${ }^{23}$

\section{CONCLUSIONS}

In conclusion, during $\mathrm{IH}$, a significant number of ICU physicians still use a postdialysis schedule of aminoglycoside administration despite a predialysis schedule of administration significantly reduceing the interval time to successful aminoglycoside redosing.

\section{ACKNOWLEDGMENTS}

We thank the study participants and the clinical and clerical teams involved in this study. We thank the French Ministry of Health, which funded the study. Alexandre Boyer, Jean-François Timsit, Kada Klouche, Emmanuel Canet, Thuy-nga Phan, Julien Bohé, Sebastien Rubin, Arthur Orieux, and Alexandre Lautrette participated in the acquisition and analysis of data. Alexandre Boyer, Jean-François Timsit, Sebastien Rubin, Didier Gruson, and Bertrand Souweine participated in the interpretation of data and drafting of the article. Alexandre Boyer, Didier Gruson, and Bertrand Souweine wrote the manuscript.

\section{FUNDING SOURCES}

This study was funded by grants from the French Ministry of Health (Programme Hospitalier de Recherche Clinique National 2008 ELVIS and Programme Hospitalier de Recherche Clinique Interregional 2009 ESCAPE).

\section{CONFLICTS OF INTEREST}

The authors have indicated that they have no conflicts of interest regarding the content of this article.

\section{REFERENCES}

1. Cartin-Ceba R, Haugen EN, Iscimen R, Trillo-Alvarez C, Juncos L, Gajic O. Evaluation of "Loss" and "End stage renal disease" after acute kidney injury defined by the Risk, Injury, Failure, Loss and ESRD classification in critically ill patients. Intensive Care Med. 2009;35:2087-2095.

2. Hoste EA, Bagshaw SM, Bellomo R, Cely CM, Colman R, Cruz DN, et al. Epidemiology of acute kidney injury in critically ill patients: the multinational AKI-EPI study. Intensive Care Med. 2015;41:1411-1423.

3. Drusano GL, Ambrose PG, Bahvnani SM, Bertino JS, Nafziger AN, Louie A. Back to the future: using aminoglycosides again and how to dose them optimally. Clin Infect Dis. 2007;45:753-760. 
4. Picard W, Bazin F, Clouzeau B, Bui HN, Guilhon E, Vargas F, et al. Propensity-based study of aminoglycoside nephrotoxicity in patients with severe sepsis or septic shock. Antimicrob Agents Chemother. 2014;28:7468-7474.

5. Teigen MM, Duffull S, Dang L, Johnson DW. Dosing of gentamicin in patients with end-stage renal disease receiving hemodialysis. J Clin Pharmacol. 2006;46:1259-1267.

6. Vercaigne LM, Ariano RE, Zacharias JM. Bayesian pharmacokinetics of gentamicin in a hemodialysis population. Clin Pharmaokinet. 2004;43:205-210.

7. Dager WE, King JH. Aminoglycosides in intermittent hemodialysis: pharmacokinetics with individual dosing. Ann Pharmacother. 2006;40:9-14.

8. Product Information: gentamicin intramuscular injection solution, intravenous injection solution, gentamicin intramuscular injectionsolution, intravenous injection solution. Fresenius Kabi USA, LLC(per DailyMed), Lake Zurich, IL, 2013

9. Heintz BH, Thompson GR, Dager WE. Clinical experience with aminoglycosides in dialysis-dependent patients: risk factors for mortality and reassessment of current dosing practices. Ann Pharmacother. 2011;45:1338-1345.

10. Dang L, Duffull S. Development of a semi-mechanistic model to describe the pharmacokinetics of gentmaicin in patients receiving hemodialysis. J Clin Pharmacol. 2006;46:662-673.

11. Kirkpatrick CMJ, Duffull SB, Begg EJ. Once daily aminoglycoside therapy: potential ototoxicity. Antimicrob Agents Chemother. 1997;41:879-880.

12. Matsuo H, Hayashi J, Ono K, Andoh K, Andoh Y, Sano Y, et al. Administration of aminoglycosides to hemodialysis patients immediately before dialysis: a new dosing modality. Antimicrob Agents Chemother. 1997;41:2597-2601.

13. Arancibia A, Baillarie D, Bravo M, ChavezJ. Disposition kinetics of dibekacin in patients with renal failure and in patients undergoing hemodialysis. Int J Clin Pharmacol Ther. 1995;33:623-627.

14. Franck B, Monchaud C, Saint-Marcoux F, Rérolle JP, Allard J, Allot V, Marquet P, Essig M, Woillard JB. Population pharmacokinetics of gentamicin in haemodialysis patients: modelling, simulations and recommendations. EurJ Clin Pharmacol. 2020;76:947-955.

15. Veinstein A, Venisse N, Badin J, Pinsard M, Robert R, Dupuis A. Gentamicin in hemodialyzed critical care patients: early dialysis after administration of a high dose should be considered. Antimicrob Agents Chemother.

2013;57:977-982.
16. Vogelman B, Gudmundsson S, Leggett J, Turnidge J, Ebert S, Craig WA. Correlation of antimicrobial pharmacokinetic parameters with therapeutic efficacy in an animal model. J Infect Dis. 1988;158:831-847.

17. Carcas AJ, Sevillano D, González N, Alou L, Gómez-Gil R, Muñoz M, Llanos L, Sanchez-Villanueva RJ,

Gonzalez-Parra E, Giménez MJ, Aguilar L. Evaluating the optimal time for amikacin administration with respect to haemodialysis using an in vitro pharmacodynamic simulation against epidemic nosocomial OXA-48 producing Klebsiella pneumoniae ST405 strains. Journal of Global Antimicrobial Resistance. 2019;19:241-251.

18. Souweine B, Lautrette A, Gruson D, Canet E, Klouche K, Argaud L, et al. Ethanol lock and risk of hemodialysis catheter infection in critically ill patients. A randomized controlled trial. Am J Respir Crit Care Med. 2015;191:1024-1032.

19. Bone RC, Balk RA, Cerra FB, Dellinger RP, Fein AM, Knaus WA, Schein RM, Sibbald WJ. Definitions for sepsis and organ failure and guidelines for the use of innovative therapies in sepsis. The ACCP/SCCM Consensus Conference Committee. American College of Chest Physicians/Society of Critical Care Medicine. Chest. 1992;101:1644-1655.

20. Nix DE, Goodwin SD, Peloquin CA, Rotella DL, Schentag JJ. Antibiotic Tissue Penetration and Its Relevance: Impact of Tissue Penetration on Infection Response. Antimicrob Agents Chemother. 1991;35:1953-1959.

21. Sowinski KM, Magner SJ, Lucksiri A, Scott MK, Hamburger RJ, Mueller BA. Influence of hemodialysis on gentamicin pharmacokinetics, removal during hemodialysis, and recommended dosing. Clin J Am Soc Nephrol. 2008;3:355-361.

22. Aronoff GR, Berns JS, Brier ME. Drug prescribing in renal failure: dosing guidelines for adults and children. Philadelphia: ACP Press; 2007.

23. Amin NB, Padhi ID, Touchette MA, Patel RV, Dunfee TP, Anandan JV. Characterization of gentamicin pharmacokinetics in patients hemodialyzed with high-flux polysulphone membranes. Am J Kidney Dis. 1999;34:222-227.

Address correspondence to: Alexandre Boyer, CHU Bordeaux, Service de Médecine Intensive Réanimation, F-33000 Bordeaux, France.E-mail: alexandre.boyer@chu-bordeaux.fr. 